\title{
Vitamin $D$ requirement in pregnancy to prevent deficiency in neonates: a randomised trial
}

\author{
Mehrdad Shakiba ${ }^{1}, \mathrm{MD}$, Mohamad Reza Iranmanesh ${ }^{1}$, MD
}

\begin{abstract}
INTRODUCTION The exact amount of vitamin D required for pregnant women to adequately supply the foetus during pregnancy is still unclear. This randomised trial attempted to determine the optimal dose of vitamin D necessary during pregnancy in order to attain a vitamin D level $>20 \mathrm{ng} / \mathrm{mL}$ in neonates.

METHODS A total of 51 healthy, pregnant women in Yazd, Iran, were recruited in 2009. Of these, 34 were randomised to receive either 50,000 IU (Group A) or 100,000 IU (Group B) of vitamin D3 per month from the second trimester of pregnancy. The remaining 17 pregnant women, who formed the third group (Group C) and were found to have vitamin D deficiency, were initially treated with 200,000 IU of vitamin $D_{3}$, following which the dose was adjusted to 50,000 IU per month. 25-hydroxyvitamin D (25[OH]D) in cord blood was measured by chemiluminescence immunoassay, and a serum $25(\mathrm{OH})$ D level $<20 \mathrm{ng} / \mathrm{mL}$ was defined as deficiency.

RESULTS All the pregnant women had a vitamin $D$ level $<30 \mathrm{ng} / \mathrm{mL}$ at the beginning of the second trimester. The neonates of $76 \%$ of women from Group A had sufficient levels of 25(OH)D. All the neonates born to women in Groups B and C had 25(OH)D $>20 \mathrm{ng} / \mathrm{mL}$. No side effects were observed in our participants during the period of vitamin D supplementation.

CONCLUSION A vitamin $\mathrm{D}_{3}$ dose $>50,000 \mathrm{IU} / \mathrm{month}$ is required during the second and third trimesters of pregnancy for vitamin D-deficient pregnant women in order for their neonates to achieve serum 25(OH)D levels $>20 \mathrm{ng} / \mathrm{mL}$. Supplementation with $<50,000 \mathrm{IU} /$ month is insufficient to ensure a vitamin D level $>20 \mathrm{ng} / \mathrm{mL}$ in all neonates born to vitamin D-deficient pregnant women.
\end{abstract}

Keywords: 25-hydroxyvitamin D, neonate, pregnancy, vitamin D

\section{INTRODUCTION}

Vitamin D inadequacy and deficiency are global problems, and their prevalence is high even in developed countries. In particular, pregnant women have been identified as a high-risk group, with global reports citing that $20 \%-80 \%$ of pregnant women may suffer from vitamin D inadequacy.(1) Evidence from animal studies, with some supportive findings from human studies, suggests that maintaining adequate levels of vitamin $\mathrm{D}$ and calcium during pregnancy may decrease the risks of preeclampsia. ${ }^{(2,3)}$ Moreover, gestational diabetes mellitus appears to be more common in pregnant women with a low vitamin D status. ${ }^{(2,3)}$ There is also evidence suggesting that vitamin D-deficient women are at increased risk of bacterial vaginosis and Caesarean sections, ${ }^{(4)}$ both of which have potentially adverse effects on the neonate. Some well-known consequences of severe clinical vitamin D deficiency in pregnancy can be life-threatening to the neonate, while lesser degrees of hypovitaminosis D may have important immediate and long-term implications for offspring health. Prematurity, low birth weight and lower bone density, as well as later sequelae such as higher rates of lower respiratory tract infection in the first months of life, asthma, diabetes mellitus, autism and dental problems, are examples of neonatal outcomes known to be related to vitamin D deficiency in pregnancy. ${ }^{(5-12)}$

25-hydroxyvitamin $\mathrm{D}(25[\mathrm{OH}] \mathrm{D})$ is the main circulatory component of vitamin $\mathrm{D}$, and its measurement is used as a marker

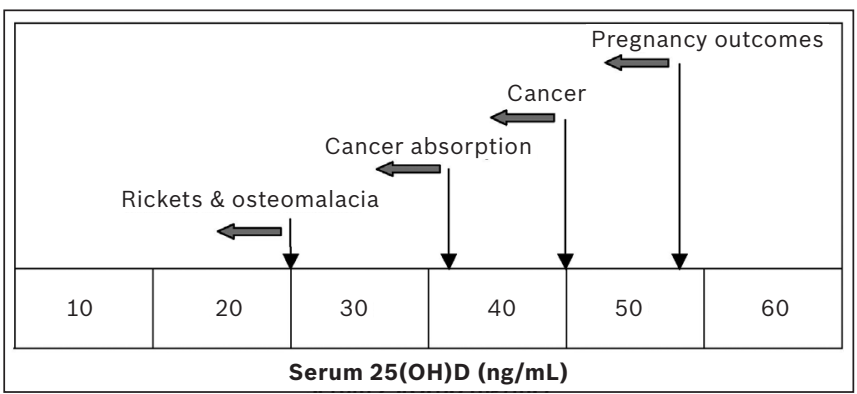

Fig. 1 Chart shows the 25-hydroxyvitamin $D$ levels required for the optimal action of vitamin D.

for defining vitamin D status. Due to the different actions of vitamin $\mathrm{D}$, it is often difficult to arrive at an overarching consensus on the optimal serum level of $25(\mathrm{OH})$ D. Fig. 1 shows some cut-off points of serum 25(OH)D for optimal action of vitamin D, as proposed by Heaney. ${ }^{(13)}$ The effects of vitamin D status on pregnancy outcomes such as prematurity, vaginosis, Caesarean section and gestational diabetes mellitus were recently reported in a study by Dror. ${ }^{(3)}$

The exact amount of vitamin D required during pregnancy has not been defined. Evidence shows that the recommended dosages of prenatal care vitamins is insufficient to effect a significant change in the serum $25(\mathrm{OH}) \mathrm{D}$ levels of pregnant women; in vitamin D-deficient pregnant women, amounts $<1,000 \mathrm{IU}$ could not maintain a sufficient level at the end of pregnancy. ${ }^{(14,15)}$ Our protocol for vitamin $\mathrm{D}_{3}$ administration in

${ }^{1}$ Paediatric Department, Shahid Sadoughi Medical University, Yazd, Iran

Correspondence: Dr Mehrdad Shakiba, Assistant Professor, Paediatric Department, Shahid Sadoughi Medical University, Avicenna St, Yazd, Iran. shakiba@ssu.ac.ir 
pregnant women was based on Holick's recommendation, in order to maintain serum 25(OH)D levels > $30 \mathrm{ng} / \mathrm{mL}$ with other forms of vitamin D supplementation during pregnancy. ${ }^{(16,17)}$

The present study aimed to determine the optimal dosage of vitamin D supplementation necessary in pregnant women in order to prevent vitamin D deficiency and to maintain a serum $25(\mathrm{OH}) \mathrm{D}$ level $>20 \mathrm{ng} / \mathrm{mL}$ in neonates from a locality known to have a high prevalence of vitamin D deficiency. ${ }^{(18)}$

\section{METHODS}

The study was carried out on 51 healthy, pregnant women from the beginning of their second trimester of pregnancy during the autumn and winter of 2009 in Yazd (31 $\left.53^{\prime} 50^{\prime \prime} \mathrm{N} / 54^{\circ} 22^{\prime} 04^{\prime \prime} \mathrm{E}\right)$, Iran, where $>90 \%$ of the days are sunny and well-organised prenatal care is available to most pregnant women. The women were randomly recruited from two primary care clinics. The first measurement of serum 25(OH)D was done at the beginning of the second trimester of pregnancy using chemiluminescence immunoassays (DiaSorin, spA, Via Crescentino, Vercelli, Italy). Vitamin $\mathrm{D}_{3}$ for supplementation was obtained locally (Alhavi Pharmaceutical Co, Tehran, Iran). The study was approved by the ethics committee of the Shahid Sadoughi Medical University, Yazd, Iran.

The participants were distributed into three groups. Of the 51 participants, 34 were randomly classified into two groups - Group A received 50,000 IU/month and Group B received $100,000 \mathrm{IU} / \mathrm{month}(50,000 \mathrm{IU}$ every two weeks) of vitamin $\mathrm{D}_{3}$ supplementation. The remaining 17 women, with serum $25(\mathrm{OH}) \mathrm{D}$ levels $<20 \mathrm{ng} / \mathrm{mL}$, were allocated into the third group, Group C. These vitamin D-deficient women in Group C were recruited from among 32 pregnant women who had been checked for vitamin-D deficiency prior to enrolment in the study. The women in Group $\mathrm{C}$ were treated with a total of 200,000 IU (50,000 IU/week for four weeks) of vitamin $D_{3}$, followed by supplementation with 50,000 IU/month. The calcium levels of all the women were checked in the delivery room.

Obstetricians and midwives conducted monthly visits to ensure that the participants adhered to the recommended dosage of vitamin $\mathrm{D}_{3}$. At the time of delivery, the level of $25(\mathrm{OH}) \mathrm{D}$ in cord blood was measured, and a paediatrician examined the neonate for possible anomalies and recorded the anthropometric measurements. The weight and rate of prematurity of the neonates were compared against the local records of birth certificates from the health centre for the Yazd province. In 2005, the mean weight of neonates in Yazd province was $3,130 \pm 106 \mathrm{~g}$, with a prematurity rate of $8 \%$, according to the local annual report of the health centre in Yazd, Iran. ${ }^{(19)}$ Samples were allocated as $51(\beta=80 \% ; \alpha=5 \%$; standard deviation $=10 ; d=2.8)$. Normality of the variable $(25[\mathrm{OH}] \mathrm{D})$ was checked using the Shapiro-Wilk test (Group A, p < 0.05). The Mann-Whitney $U$ test was used for comparing the means between groups.
Table I. Distribution of women on different amounts of vitamin D supplementation regimens during pregnancy, based on the level of 25-hydroxyvitamin D (25 [OH]D) in cord blood.

\begin{tabular}{lccc}
\hline Group & \multicolumn{3}{c}{ 25(OH)D level in cord blood [No. (\%)] } \\
\cline { 2 - 4 } & $\begin{array}{c}>\mathbf{3 0} \mathbf{~ n g / m L} \\
\text { (Sufficient) }\end{array}$ & $\begin{array}{c}\text { 20-30 } \mathbf{~ n g / m L ~} \\
\text { (Insufficient) }\end{array}$ & $\begin{array}{c}<\mathbf{2 0} \mathbf{~ n g / m L} \\
\text { (Deficient) }\end{array}$ \\
\hline Group A & $6(35)$ & $7(41)$ & $4(24)$ \\
Group B & $10(59)$ & $7(41)$ & $0(0)$ \\
Group C & $14(82)$ & $3(18)$ & $0(0)$ \\
\hline
\end{tabular}

Group A: 50,000 IU/mth; Group B: 100,000 IU/mth; Group C: deficiency therapy $+50,000 \mathrm{IU} / \mathrm{mth}$

Table II. Levels of 25-hydroxyvitamin D (25[OH]D) in the cord blood of neonates born to women on vitamin $D$ supplementation.

\begin{tabular}{lcc}
\hline Group & $\mathbf{2 5}(\mathbf{O H}) \mathbf{D}$ level $(\mathbf{n g} / \mathbf{m L})$ & p-value* $^{*}$ \\
\hline Group A & $25 \pm 7(17-42)$ & 0.003 \\
Group B & $32 \pm 12(24-54)$ & \\
\hline
\end{tabular}

Data is presented as mean \pm standard deviation (range). * Based on MannWhitney test

Group A: 50,000 IU/mth; Group B: 100,000 IU/mth

\section{RESULTS}

The mean age of the participants was $25 \pm 3$ years. $76 \%$ of the pregnant women were either primigravida or secundigravida, and all the participants were educated. Initial measurements of serum $25(\mathrm{OH}) \mathrm{D}$ at the beginning of the second trimester of pregnancy revealed that all 51 participants had a serum 25(OH)D level $<30 \mathrm{ng} / \mathrm{mL} ; 53 \%$ of participants from Group A and 65\% from Group B had initial levels $<20 \mathrm{ng} / \mathrm{mL}$. The mean serum 25(OH)D levels in groups A, B and C were $16 \pm 7.4 \mathrm{ng} / \mathrm{mL}, 18 \pm 7.8 \mathrm{ng} / \mathrm{mL}$ and $7 \pm 3.0 \mathrm{ng} / \mathrm{mL}$, respectively. Calcium levels (range 8.6-10.3 $\mathrm{mg} / \mathrm{dL}$ ) were in the normal range for all participants.

Table I summarises the distribution of women on the different vitamin D supplementation regimens during pregnancy, based on the serum 25(OH)D levels in cord blood. The mean $25(\mathrm{OH}) \mathrm{D}$ levels found in the cord blood from Groups A and B are shown in Table II. Higher levels of $25(\mathrm{OH}) \mathrm{D}$ are found in the cord blood from Group B than from Group A. The mean $25(\mathrm{OH}) \mathrm{D}$ level in the cord blood from Group C was $35 \pm 8$ (range 27-51) $\mathrm{ng} / \mathrm{mL}$, which was significantly higher than that in Group A (Mann-Whitney U test; $\mathrm{p}<0.001$ ) and Group B (MannWhitney $U$ test; $p<0.005$ ).

There was no significant difference in the average birth weights of neonates among the three groups (Group A: 3,279 g; Group B: 3,579 g; Group C: 3,367 g; $p=0.4$ ). The average length of the neonates in the three groups also did not differ significantly (Group A: 51.9 cm; Group B: 52.1 cm; Group C: 52.0 cm; $p=0.8)$. The pregnant women were seen regularly during prenatal follow-up, and none of the participants complained about having to consume the vitamin D supplements.

\section{DISCUSSION}

The present study confirms previous reports of high rates of vitamin $\mathrm{D}$ deficiency among pregnant women in our region. ${ }^{(20)}$ 
More than $60 \%$ of the pregnant women in our study were vitamin $\mathrm{D}$ deficient and none of those studied had an ideal vitamin D level (> $30 \mathrm{ng} / \mathrm{mL}$ ) prior to vitamin D supplementation. This is similar to the findings of reports from the region. ${ }^{(20)}$ This deficiency could be due to lifestyle factors such as a preference for indoor activities, the lack of intake of vitamin D-fortified food, avoidance of sun exposure (for cosmetic reasons or fear of skin malignancy), and the practice of veiling among Iranian women, which was an aggravating factor for vitamin-D deficiency in our cohort.

Our findings support the general consensus that higher doses of vitamin $\mathrm{D}$ than the routinely recommended dose of $1,000 \mathrm{IU} /$ day are necessary from the beginning of the second trimester of pregnancy in vitamin D-deficient pregnant women in order to prevent vitamin D deficiency in both mothers and their neonates. A high correlation between the vitamin D levels seen among pregnant women and their neonates (correlation of maternal and neonatal $25(\mathrm{OH}) \mathrm{D} ; \mathrm{r}=55 \%)^{(20)}$ suggests that this assumption can be extended to the pregnant women in our cohort as well. This finding is in agreement with that of a previous study, (21) but it is at odds with a recent recommendation by the Institute of Medicine of the National Academies, USA, which proposed a daily intake of $400 \mathrm{IU} /$ day during pregnancy. ${ }^{(22)}$ It is possible that lower doses of vitamin D may be appropriate for societies where pregnant women are not severely vitamin D deficient or receive vitamin $\mathrm{D}$ from other food sources and through skin exposure. The lower dosage suggested by the American study might not be sufficient in regions where the aforementioned limitations are relevant. A study by Datta et al showed that vitamin D-deficient pregnant women who consumed less than 1,600 IU/day of vitamin D could not maintain sufficiency at the end of pregnancy. ${ }^{(14)}$ Studies have also suggested that vitamin D deficiency is present even among pregnant women in developed countries, and it is therefore possible that the recommended daily intake of $400 \mathrm{IU} /$ day for such women may only achieve minimal increases in serum $25(\mathrm{OH}) \mathrm{D}$ levels even with supplementation. ${ }^{(23,24)}$

We found that a serum level of $25(\mathrm{OH}) \mathrm{D}>20 \mathrm{ng} / \mathrm{mL}$ was achievable in all neonates when the pregnant women's intake of vitamin D was increased to 50,000 IU every two weeks ( 3,300 IU/day), or when an initial bolus dose of 200,000 IU followed by 50,000 IU/month was taken during the course of the pregnancy. A thorough study is required to determine the effectiveness of these two approaches, specifically from a clinical point of view, as well as to assess the long-term effects of such supplementation. Our findings are similar to those of other studies, which reported that vitamin $\mathrm{D}_{3}$ supplementation $>2,000 \mathrm{IU} /$ day is necessary to obtain a sufficient serum level of vitamin $\mathrm{D}$ in pregnant women and their neonates. ${ }^{(25,26)}$ Where other recommendations are concerned, for instance the Canadian Academy of Paediatrics, which recommends a vitamin D supplementation of 2,000 IU/day for the entire duration of pregnancy, (27) it would be better to individually assess the best possible approach for each woman. It might also be advisable to assess the vitamin D status of pregnant women from the beginning of pregnancy and treat them individually instead of using a predetermined prescription for all patients.

Our results also suggested a low rate of prematurity among neonates born to women who have been supplemented with vitamin D. Among the 51 women who received vitamin D-supplementation, only $1(2 \%)$ neonate was delivered prematurely (95\% confidence interval $[\mathrm{Cl}] 1.3-5.5)$. This is in contrast to the $8 \%$ rate of prematurity in our region. ${ }^{(19)}$ We also found that the mean weight of neonates born to women with vitamin D supplementation (mean weight, 3,408 $\pm 432 \mathrm{~g}$ ) was higher than that of infants born in Yazd ( $t$-test; $95 \% \mathrm{Cl}$ 189-376; $p=0.0005)$. These findings are in agreement with recent media reports of a high-quality clinical trial in the USA, where vitamin D was found to be associated with a lower risk of premature birth. ${ }^{(28)}$

This study is, however, not without its limitations. First, there was no placebo group with which to compare the results of the test groups against. Second, as the study ascertained only laboratory assessments of serum levels of $25(\mathrm{OH}) \mathrm{D}$ in pregnant women and their neonates without any long-term clinical evaluation, we could not establish the long-term effects of vitamin D supplementation in pregnant women. It is thus possible that the long-term effects of vitamin D supplementation might be more important than its immediate outcomes. Third, this study did not collect any information on the nutritional status or dietary habits of the participants other than ascertaining that they were not on diets enriched with vitamin D. Fourth, the pregnant women selected for the study were not randomly recruited from all primary care clinics in the city. Finally, as we did not have a control group, it was not possible to attribute our findings on the prematurity and weight of neonates born to pregnant women receiving vitamin $\mathrm{D}$ supplementation solely to vitamin D. However, although it is likely that the veiling of pregnant women in Iran could prove to be a limiting factor for the extrapolation of our results to pregnant women from other regions, it may still be possible to apply our findings to areas with fewer sunny days.

Our results confirm that in a region where the prevalence of vitamin $\mathrm{D}$ deficiency in pregnant women is high, consumption of vitamin $\mathrm{D}_{3}>50,000 \mathrm{IU} /$ month (> 1,600 IU/day) is needed from the second trimester of pregnancy in order to maintain a serum $25(\mathrm{OH}) \mathrm{D}$ level $>20 \mathrm{ng} / \mathrm{mL}$ in neonates. Such supplementation may also help to reduce the risk of premature birth among these women. Such an approach may have implications not only for the duration of intrauterine life but also for neonatal outcomes in the first crucial months of life after birth. This is especially so because it would take over two months of oral vitamin D supplementation in order for infants born to vitamin D-deficient women to achieve sufficient serum vitamin D levels. 


\section{ACKNOWLEDGEMENTS}

The authors wish to thank the participants who took part in the study. We are also grateful to Mrs Shamsi for her help with statistical analysis. This article presents the results of research conducted by Iranmanesh MR under the supervision of Shakiba M.

\section{REFERENCES}

1. Mulligan ML, Felton SK, Riek AE, Bernal-Mizrachi C. Implications of vitamin D deficiency in pregnancy and lactation. Am J Obstet Gynecol 2010; 202:429.e1-9.

2. Kovacs CS. Vitamin D in pregnancy and lactation: maternal, fetal, and neonatal outcomes from human and animal studies. Am J Clin Nutr 2008; 88:520S-528S

3. Dror DK. Vitamin D status during pregnancy: maternal, fetal, and postnatal outcomes. Curr Opin Obstet Gynecol 2011; 23:422-6.

4. Hensel KJ, Randis TM, Gelber SE, Ratner AJ. Pregnancy-specific association of vitamin D deficiency and bacterial vaginosis. Am J Obstet Gynecol 2011; 204:41.e1-9.

5. Bodnar LM, Catov JM, Zmuda JM, et al. Maternal serum 25-hydroxyvitamin D concentrations are associated with small-for-gestational age births in white women. J Nutr 2010; 140:999-1006.

6. Leffelaar ER, Vrijkotte TG, van Eijsden M. Maternal early pregnancy vitamin $D$ status in relation to fetal and neonatal growth: results of the multi-ethnic Amsterdam Born Children and their Development cohort. Br J Nutr 2010; 104:108-17.

7. Mahon P, Harvey N, Crozier S, et al. Low maternal vitamin D status and fetal bone development: cohort study. J Bone Miner Res 2010; 25:14-9.

8. Cole ZA, Gale CR, Javaid MK, et al. Maternal dietary patterns during pregnancy and childhood bone mass: a longitudinal study. J Bone Miner Res 2009; 24:663-8.

9. Weiss ST, Litonjua AA. Childhood asthma is a fat-soluble vitamin deficiency disease. Clin Exp Allergy 2008; 38:385-7.

10. Grant WB, Soles CM. Epidemiologic evidence supporting the role of maternal vitamin D deficiency as a risk factor for the development of infantile autism. Dermatoendocrinol 2009; 1:223-8.

11. Eyles DW, Feron F, Cui X, et al. Developmental vitamin D deficiency causes abnormal brain development. Psychoneuroendocrinology 2009; 34(Suppl 1):S247-57.

12. Marjamäki L, Niinistö S, Kenward MG, et al. Maternal intake of vitamin D during pregnancy and risk of advanced beta cell autoimmunity and type 1 diabetes in offspring. Diabetologia 2010; 53:1599-607.

13. Heaney RP. Defining deficiency of vitamin D [online]. Available at: http:// www.cli-online.com/index.php?id=2975. Accessed November 3, 2012.
14. Datta S, Alfaham M, Davies DP, et al. Vitamin D deficiency in pregnant women from a non-European ethnic minority population--an interventional study. BJOG 2002; 109:905-8.

15. Hollis BW, Wagner CL. Vitamin D requirements during lactation: highdose maternal supplementation as therapy to prevent hypovitaminosis D for both the mother and the nursing infant. Am J Clin Nutr 2004; 80(6 Suppl):1752S-8S

16. Holick MF. Vitamin D deficiency. N Engl J Med 2007; 357:266-81.

17. Hollis BW, Wagner CL. Vitamin D requirements and supplementation during pregnancy. Curr Opin Endocrinol Diabetes Obes 2011; 18:371-5.

18. van Schoor NM, Lips P. Worldwide vitamin D status. Best Pract Res Clin Endocrinol Metab 2011; 25:671-80.

19. Eastern Mediterranean Regional Health System Observatory. EMRO 3: Health Status and Demographics. In: World Health Organization - Eastern Mediterranean Regional Health System Observatory [online]. Available at: http://gis.emro.who.int/HealthSystemObservatory/PDF/Iran/Health\%20 status\%20and\%20demographics.pdf. Acessed May 15, 2013.

20. Kazemi A, Sharifi F, Jafari N, Mousavinasab N. High prevalence of vitamin $\mathrm{D}$ deficiency among pregnant women and their newborns in an Iranian population. J Womens Health (Larchmt) 2009; 18:835-9.

21. Saadi HF, Dawodu A, Afandi BO, et al. Efficacy of daily and monthly highdose calciferol in vitamin D-deficient nulliparous and lactating women. Am J Clin Nutr 2007; 85:1565-71.

22. Institute of Medicine of the National Academies. Dietary Reference Intakes for Calcium and Vitamin D [online]. Available at: www.iom.edu/ Reports/2010/Dietary-Reference-Intakes-for-Calcium-and-Vitamin-D. aspx. Accessed August 5, 2011.

23. Mallet E, Gügi B, Brunelle $P$, et al.Vitamin D supplementation in pregnancy: a controlled trial of two methods. Obstet Gynecol 1986; 68:300-4.

24. Heaney RP, Davies KM, Chen TC, Holick MF, Barger-Lux MJ. Human serum 25-hydroxycholecalciferol response to extended oral dosing with cholecalciferol. Am J Clin Nutr 2003; 77:204-10.

25. Sahu M, Das V, Aggarwal A, et al. Vitamin D replacement in pregnant women in rural north India: a pilot study. Eur J Clin Nutr 2009, 63:1157-9.

26. Yu CK, Sykes L, Sethi M, Teoh TG, Robinson S. Vitamin D deficiency and supplementation during pregnancy. Clin Endocrinol (Oxf) 2009; 70:685-90

27. Canadian Paediatric Society. Vitamin D supplementation: Recommendations for Canadian mothers and infants. Paediatr Child Health 2007; 12:583-98.

28. Hollis B, Wagner C .Vitamin D 'may cut premature birth risk and protect new born babies' times 2009. Available at: www.timesonline.co.uk/tol/ news/uk/scotland/artic le6868729.ece?token=null\&offset=0\&page=1. Accessed August 5, 2011.

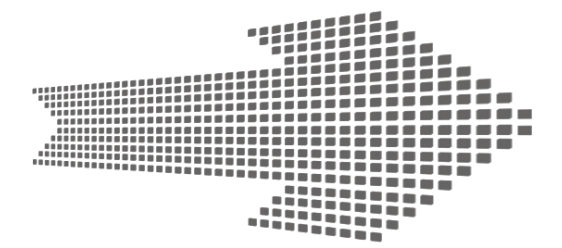

\section{Online Manuscript Submission www.editorialmanager.com/singaporemedj}

